
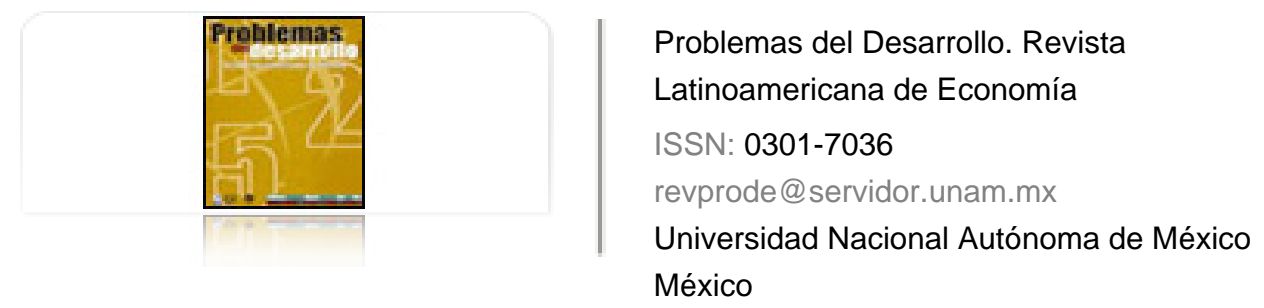

Novelo Urdanivia, Federico ¿ES VIABLE OTRA GLOBALIZACIÓN?

Problemas del Desarrollo. Revista Latinoamericana de Economía, vol. 34, núm. 134, 2003, pp. 33-48

Universidad Nacional Autónoma de México

Distrito Federal, México

Disponible en: http://www.redalyc.org/articulo.oa?id=11825944003

- Cómo citar el artículo

- Número completo

- Más información del artículo

Página de la revista en redalyc.org

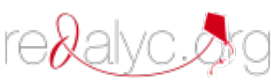

Sistema de Información Científica

Red de Revistas Científicas de América Latina, el Caribe, España y Portugal Proyecto académico sin fines de lucro, desarrollado bajo la iniciativa de acceso abierto 


\section{¿ES VIABLE OTRA GLOBALIZACIÓN?}

\section{Federico Novelo Urdanivia*}

Fecha de recepción: 14 de enero de 2003. Fecha de autorización: 2 de diciembre de 2003.

\section{Resumen}

Este trabajo analiza los determinantes económicos y políticos del orden mundial posterior a la Guerra Fría y compara el papel del poder político en los dos momentos estelares del laissezfaire mundial, el del victoriano tardío británico y el de la globalización en curso. Además, hace referencia a los saldos económicos y sociales, ya visibles, del nuevo orden global y establece las diferencias relevantes entre globalización, globalidad y globalismo, así como entre globalización e integración regional. Concluye con la propuesta de agenda de reformas al status quo, para dotarle de legitimidad y eficacia, con arreglo a las propuestas reformistas de numerosos autores.

Palabas clave: laissez-faire, globalidad y globalismo, globalización e integración regional, legitimidad, eficacia.

\section{Abstract}

This article analyzes the economic and political determinants of the world order after the Cold War and compares the role political power has played in two peak moments of world-wide laissez-faire, the late Victorian days in Britain and current globalization. It also makes reference to the already visible economic and social balances, the new global order and establishes the relevant differences between globalization, globalness and globalism, as well as globalization and regional integration. It concludes with the proposed agenda of reforms to the status quo made in order to legitimize globalization and increase its efficiency in agreement with the reformist proposals of numerous authors.

Key words: laissez-faire, globalness and globalism, globalization and regional integration, legitimacy and efficiency.

\footnotetext{
* Profesor investigador de la UAM Xochimilco.
} 


\section{Résumé}

Cette étude analyse les déterminants économiques et politiques de l'ordre mondial qui a suivi la Guerre Froide et compare le rôle du pouvoir politique aux deux moments de paroxysme du laissez-faire mondial, celui de la fin de l'époque victorienne et celui de la mondialisation actuelle. En outre, elle fait référence aux bilans économiques et sociaux, déjà visibles, du nouvel ordre mondial et établit les différences importantes entre mondialisation, mondialité et mondialisme, ainsi qu'entre mondialisation et intégration régionale. Elle conclut par la proposition d'une série de réformes au statu quo, afin de le pourvoir de légitimité et d'efficacité, dans le cadre des propositions réformistes de nombreux auteurs.

Mots-cléfs: laissez-faire, mondialité et mondialisme, mondialisation et intégration régionale, légitimité et efficacité.

\section{Resumo}

Este trabalho analisa os determinantes econômicos e políticos da ordem mundial posterior à Guerra Fria e compara o papel do poder político nos dois momentos mais importantes do laissez-faire mundial: o do vitoriano tardio britânico e o da globalização em curso. Faz referencia, também, aos saldos econômicos e sociais, já visíveis, da nova ordem global e estabelece as importantes diferenças entre globalização, globalidade e globalismo, assim como também entre globalização e integração regional. Conclui com uma proposta de agenda de reformas ao status quo, para dotá-lo de legitimidade e eficácia, segundo propostas reformistas de numerosos autores.

Palavras chave: laissez-faire, globalidade e globalismo, globalização e integração regional, legitimidade e eficácia. 
No podemos hacer retroceder la historia. Sin embargo, no deseo abandonar la creencia de que un mundo que sea una capa razonablemente pacífica de muchos colores, en la que cada una de las partes desarrolle su propia identidad cultural específica y sea tolerante hacia los demás, no es un sueño utópico.

Isaiah Berlin

\section{Introducción}

Por los excesos en su empleo, por la cantidad y variedad de aspectos que se ponen bajo su cobijo y por la consecuente y usual falta de precisión al invocarlo, el concepto globalización tiende a perder cualquier eficacia explicativa ${ }^{1}$ y a convertirse en una referencia demasiado abultada e incómoda —o irresponsablemente cómoda — al abordar los asuntos económicos, sociales, políticos y culturales involucrados y que se combinan con cierta jerarquía y con total interdependencia. La globalización, tal cual, se promueve después de la conclusión de la Guerra Fría. Es un proceso con antecedentes históricos documentables y con singularidades inéditas ${ }^{2}$ que cuentan, entre los primeros, con el predominio de un enfoque económico convencionalmente aceptado como el laissez faire y, entre las segundas, a la dimensión, variedad y profundidad de sus efectos prácticamente en la totalidad de las actividades humanas. El propósito central de este trabajo es demostrar que existe alguna diferencia en sus fuerzas impulsoras (globalidad y globalismo, de acuerdo con la clarificación —o complicación - metodológica sugerida por Ülrich Beck) ${ }^{3}$ y la cercana posibilidad de prescindir de ese globalismo, entendido como el apéndice economicista neoliberal, para colocar en ese sitio un enfoque económico con rostro humano visible; mientras que en la primera se encuentran las mejores posibilidades de convivencia racional, tolerante y pacífica.

Las razones de esta propuesta, como se verá más adelante, descansan en disponer de evidencias significativas de contradicción, tensión, cinismo e hipocresía en el predominio

Zaki Laïdi, Un mundo sin sentido, México, FCE, 1997, pp. 11-21.

Esta interpretación ciertamente se coloca a significativa distancia de otras que consideran que la globalización se inició con los desembarcos de Cristóbal Colón y Vasco da Gama, en Guanahaní y Calicut, respectivamente, y que sólo perciben al periodo de entre guerras mundial es como de desglobalización: cf. Aldo Ferrer, Historia de la globalización II. La revolución industrial y el Segundo Orden M undial, Buenos Aires, FCE, 2000, p. 9.

3 Ülrich Beck, ¿Qué es la globalización?, Barcelona, Paidós, 1998, pp. 164-181. 
de las justificaciones, promesas y prioridades, especialmente económicas, de la globalización hoy disponible, cuyo rasgo fundamental deriva del llamado Consenso de Washington. Desde 1989, se construye un decálogo exclusivamente económico que corresponde a lo que Beck denomina globalismo y el cual, en el ámbito político y académico del Tercer Mundo, se identifica con la noción de neoliberalismo. Los propósitos que estructuran el Consenso, son:

- establecer la disciplina fiscal,

- priorizar el gasto público en educación y salud,

- llevar a cabo reformas tributarias,

- establecer tasas de interés positivas determinadas por el mercado,

- lograr tipos de cambio competitivos,

- desarrollar políticas comerciales liberales,

- brindar una mayor apertura a la inversión extranjera,

- privatizar las empresas públicas,

- llevar a cabo una profunda desregulación, y

- garantizar la protección de la propiedad privada. ${ }^{4}$

\section{La política y el laissez-faire en la globalización}

En la propuesta del mal llamado Consenso, vuelve a tomar su sitio la compleja relación entre el sistema económico y la organización de la sociedad; recordemos, con Polanyi - a la hora de analizar los mercados libres_- que en lugar de una economía imbricada en las relaciones sociales, padecemos de una circunstancia en la que las relaciones sociales están superpuestas en el sistema económico. En otros términos, el éxito del marxismo vulgar consiste en que convierte a la conducta humana en variable dependiente de la base económica. A este respecto, Beck sugiere: "Su dogma no es que se haya de actuar económicamente, sino que todo - política, economía, cultura — ha de supeditarse al primado de la economía. En este aspecto el globalismo neoliberal se parece a su enemigo mortal, el marxismo".5

Este artículo, en correspondencia con su propósito de largo alcance y con su tema específico, parte de una reiterada y poco atendida advertencia, enunciada por Karl Polanyi (1992), John Gray (2000)), Ülrich Beck (1998) y Zaki Laïdi (1997), que constituye la más significativa idea fuerte de este texto, a saber: el carácter político y la intensa utilización del poder del Estado para arribar a los dos momentos estelares del laissez faire, el que protagonizó la Gran Bretaña al mediar el siglo XIX y el que aparece como el corazón del

4 Wilfrido R. Bolaños G., Cuatro enfoques sobre la globalización, UAM-X, 2002, mimeo., p. 28.

5 Beck, ¿Qué es la globalización?, op. cit., p. 169. 
proceso globalizador en curso, cuyos impulsos fundamentales - la libre competencia en aquel entonces y, muy especialmente, la que se da entre mercados desregulados queprovienen, hoy, de Estados Unidos de América.

De manera indicativa, se incorpora la afirmación de Polanyi, relativa a este aspecto fundamental:

Lo que abrió y mantuvo abierto el camino hacia el libre mercado fue el enorme aumento de un intervencionismo continuado, centralmente organizado y controlado [...] Así como la invención de maquinaria ahorradora de mano de obra no había disminuido sino incrementado los usos del trabajo humano - contra lo esperado- la introducción de mercados libres, lejos de eliminar la necesidad del control, la regulación y la intervención, aumentaba enormemente su alcance. ${ }^{6}$

Por su parte, Gray reflexiona sobre el mismo aspecto de la siguiente manera:

Los mercados con limitaciones son la norma en toda sociedad, mientras los libres mercados son producto del artificio, de la estrategia y de la coerción política. El laissez faire debe planificarse centralmente; los mercados regulados simplemente existen. El libre mercado no es, como los pensadores de la "nueva derecha" han imaginado o afirmado, un don de la evolución social. Es un producto de la ingeniería social y de una inquebrantable voluntad política [...] el libre mercado ha usado el poder del Estado para alcanzar sus fines pero ha debilitado las instituciones en aspectos vitales. En todos los casos, las políticas de libre mercado perdieron legitimidad política y al mismo tiempo provocaron cambios económicos y sociales irreversibles y no modificables mediante procedimientos democráticos. ${ }^{7}$

Estos razonamientos, de calidad y profundidad similares a los que Keynes previó para el fin del laissez faire, muestran la forma en la que la imposición del libre comercio se aparta de cualquier evolución virtuosa de la organización económica y social. Además, ha requerido, tanto ayer como hoy, de un sólido apoyo gubernamental para establecerse y mantenerse de manera predominante en el sistema económico internacional.

Para Keynes, al lado de la política, la religión, la economía y la ineptitud de los administradores públicos, las innovaciones de Darwin también apuntaban al laissezfaire:

Nada podía parecer más opuesto que la vieja y la nueva doctrinas, la doctrina que vería al mundo como la obra de relojero divino y la doctrina que parecía sacar todas las cosas de la casualidad, del caos y de los viejos tiempos. Pero en aquel momento las nuevas ideas apuntalaron las viejas. Los economistas estaban enseñando que la riqueza, el comercio y la maquinaria eran las criaturas de la libre competencia y que la libre competencia hizo a Londres. Pero los darwinianos pudieron ir más lejos que eso: la libre competencia había hecho al hombre. El ojo humano ya no era la demostración del proyecto, discurriendo milagrosamente todas las cosas con la mejor intención; era el logro máximo de la casuali-

6 Karl Polanyi, La gran transformación. Los orígenes políticos y económicos de nuestro tiempo, M éxico, FCE, 1992, p. 146.

7 John Gray, Falso amanecer. Los engaños del capitalismo global, Barcelona, Paidós, 2000, pp. 30-37. 
dad, actuando en condiciones de libre competencia y laissez faire. El principio de la supervivencia del más apto podía considerarse como una amplia generalización de la economía ricardiana. Las interferencias socialistas venían a ser, a la luz de esta síntesis más completa, no sólo inconvenientes, sino sacrílegas, como calculadas para retrasar el movimiento progresivo del vigoroso proceso por medio del cual nosotros mismos habríamos salido como Afrodita del limo primitivo del océano. ${ }^{8}$

Keynes inicia la demoledora crítica contra los principios del laissez faire, advirtiendo que la belleza y simplicidad de una teoría semejante son tan grandes que es fácil olvidar que no se deduce de los hechos, sino de una hipótesis incompleta introducida en aras de la simplicidad. En un momento histórico que hacía del laissez faire un cuerpo teórico prescindible, John M. Ferguson hace referencia a la crítica keynesiana de esa teoría en términos francamente descalificadores: "En todo esto estaba simplemente repitiendo lo obvio, ya que el laissez faire, en el sentido que le había dado Adam Smith, ni siquiera había sobrevivido al fin del siglo XIX en ninguna parte del globo terráqueo". ${ }^{9}$ La evidencia disponible, sin embargo, muestra que el laissez faire, en el sentido que le había dado Adam Smith, resucitó y se ha hecho visible en el despunte del siglo XXI en todo el globo terráqueo.

En el cuerpo de este texto, de manera preponderante, se juzga significativa la mención del efecto social de la competencia entre utópicos mercados autorregulados, cuyo saldo más visible es el deterioro de todos y cada uno de los mecanismos de cohesión social; a este respecto, Gray señala que:

Resulta curioso que los mismos pensadores de derecha que sostienen que los Estados son impotentes en la vida económica pusieran tantas esperanzas en la actuación estatal en ingeniería social. Todavía más incoherente es que el pensamiento de la "nueva derecha" que, al igual que el marxismo corriente, sostiene que los cambios económicos determinan el comportamiento, descuide tan sistemáticamente los efectos de liberar el mercado sobre el matrimonio, la familia y la incidencia de la criminalidad". ${ }^{10}$

Las modalidades específicas de esta competencia —en la que no es aún visible la sustitución de las añejas ventajas comparativas ricardianas por una incierta construcción de ventajas competitivas porterianas-, descansan en la fragmentación de cadenas productivas, especialmente de las grandes empresas trasnacionales, con arreglo en la búsqueda de los menores costos laborales, sociales, fiscales y ambientales. En esa forma, la remuneración al trabajo — el factor menos dinamizado en los modernos procesos de inversión-, produce la desintegración de las familias, por cuanto resulta indispensable la obtención de más de un ingreso, con el consecuente abandono de los hijos y su visible vulnerabilidad

8 John Maynard Keynes, "El fin del laissez faire (1926)", en Ensayos de persuasión, Barcelona, Crítica, Grijalvo, 1988, p. 279.

9 John M. Ferguson, Historia de la economía (1a. ed. en inglés, 1938, M éxico, FCE, 2002, p. 254.

10 John Gray, Falso..., op. cit., p. 54. 
frente a las tentaciones de la drogadicción y la práctica de actividades delictivas. En respuesta, el actual programa económico niega la disposición de recursos para poner en marcha tareas preventivas y — como en el tránsito del Estado de naturaleza hacia las primeras autocracias - promueve grandes gastos en seguridad, pública y privada, cuerpos represivos, juzgados y cárceles, sin hacerse cargo que el costo de oportunidad de tales erogaciones es el crecimiento económico y el bienestar social consecuente.

Desde mucho antes de la conclusión de la Guerra Fría, el fenómeno globalizador se ha hecho acompañar de una suerte de crepúsculo inducido de la gestión estatal, no en el terreno de la promoción de lo que el Banco Mundial — desde el comienzo de los años noventa- dio en calificar como los mercados amigables. Las tareas del Estado se muestran menguadas y menguantes en los ámbitos de la definición soberana de política económica - monetaria y fiscal — y social, al calor de las también reducidas capacidades de negociación con el FMI y las significativas repercusiones del estado de ánimo de ese organismo sobre el que define el comportamiento de otras instancias internacionales y nacionales, públicas y privadas, muy especialmente en la llamada comunidad financiera internacional.

En el evangelio del FMI no existe lugar para reconocer las notables fallas del mercado, visibles —entre otros espacios - en el carácter incompleto, asimétrico y de acceso complejo de y a la información, que arrojan los saldos de daño moral y de selección adversa. ${ }^{11}$ En ese organismo, paradójicamente público, se parte de la idea de que, por lo general, el mercado funciona bien y el Estado mal. Vale decir que, en el recurrente espacio de las medidas de ajuste económico que el FMI intenta imponer a las economías del Tercer Mundo - y a las que experimentan la transición desde regímenes autoritarios de inspiración soviética hacia la economía de mercado - es notable la ausencia de conocimientos sobre la circunstancia particular de cada sociedad y la consecuente disposición a imponer un recetario general que carga con el inconveniente de no producir resultados plausibles en el crecimiento económico, en la moderación de la pobreza, en el establecimiento de la equidad y en un desarrollo armónico con el medio ambiente. Al respecto, ya comienzan a mostrarse visibles reacciones opositoras.

En un texto de más que previsible trascendencia, menos intelectual que político, ${ }^{12}$ Joseph Stiglitz destaca la opinión de Grzegorz W. Kolodovko, ex vice primer ministro y ministro de Hacienda polaco, quien ha afirmado que el éxito de su país — notable entre las antiguas economías filosoviéticas - se debió al rechazo explícito de las doctrinas del consenso de Washington:

11 José Ayala E., Mercado, elección pública e instituciones. Una revisión de las teorías modernas del Estado, M éxico, M iguel Ángel Porrúa-FE-UNAM, 1996, pp. 37-40.

12 Joseph E. Stiglitz, El malestar en la globalización, Madrid, Taurus, 2002, 314 pp. 
Escribió Kolodovko en el New York Times: "Pero hubo otra faceta de nuestro éxito igualmente importante. Polonia no buscó la aprobación de la comunidad financiera internacional. En vez de ello, intentamos que los ciudadanos polacos apoyaran las reformas. Los salarios y pensiones fueron pagados y ajustados a la inflación. Hubo prestaciones por desempleo. Respetamos nuestra propia sociedad mientras negociábamos duro con los inversores e instituciones financieras internacionales. ${ }^{13}$

El título del artículo citado ilustra la dimensión y profundidad de la reacción polaca: "Rusia debe colocar primero a su pueblo".

\section{Integración regional, ¿con o contra el libre comercio?}

En el ánimo de sumar diversas circunstancias a la causa de la forma actual de globalización, los procesos de integración regional se han enfocado, no sin dobles intenciones y de manera equivocada, como formas expeditas (alguien las denomina digeribles) ${ }^{14}$ de impulso al gran proceso citado. En realidad, las cosas no son así.

De manera similar a la descripción de las instituciones que dieron cobijo y forma a La paz de los cien años, formulada por Karl Polanyi — libre comercio, Estado liberal, patrón oro y equilibrio entre potencias-,${ }^{15}$ la globalización de hoy pretende construir una institucionalidad, percibida como las reglas del juego, en la que tomen su sitio el libre comercio, la democracia representativa, el respeto a la interpretación occidental de los derechos humanos, el cuidado y preservación del medio ambiente y, en un sentido negativo, el combate al tránsito de enfermedades infecciosas, al terrorismo, al narcotráfico y a la migración sur-norte. Si se reconoce que, bajo formas distintas, los más relevantes procesos de integración regional han dispuesto de mecanismos que, lejos de crear, desvían comercio, ya mediante la edificación de tarifas aduaneras comunes frente a terceros países, tal como acontece con la Unión Europea y con el Mercado Común del Sur (MERCOSUR), ya con el uso de reglas de origen, como sucede con el Tratado de Libre Comercio de América del Norte (TLCAN) y, presumiblemente, acontecerá con el Área de Libre Comercio de las Américas (ALCA). Resulta evidente que, en las integraciones regionales, el libre comercio es excluido por la incorporación de instrumentos neoproteccionistas, que privilegian fuentes de abastecimiento distintas de las fuentes más eficientes, tal y como Jacob Viner (1950) define a la desviación de comercio. ${ }^{16}$ Sin asomo de duda, aquí resulta visible un importante conflicto para la evolución futura de la globalización, en virtud del desarrollo preferente de los procesos de integración regional, a los efectos de la mayor velocidad con la que se suscriben y comienzan a operar, además de los efectos, también, de la capaci-

\footnotetext{
Citado en Stiglitz, El malestar en la globalización, ibid., nota al pie, p. 230. Las cursivas son mías.

Cf. Néstor García Canclini, La globalización imaginada, M éxico, Paidós, 1999, p. 13.

Polanyi, La gran transformación, op. cit., pp. 17-32.

6 Jacob Viner, The Customs Union Issue, Nueva York, Carnegie Endowment for International Peace, 1950, capítulo IV.
} 
dad de exclusión de actores ajenos a los negocios regionales (quienes no deben ser relegados del debate ni de la toma de decisiones en los organismos e instrumentos multilaterales). Merecen destacarse dos consideraciones que adquieren el grado de contradicción: en primer lugar, aparece una notable evidencia de la hipocresía del gobierno de Estados Unidos que, con la Omnibus Trade and Competitivenness Act de 1988, que dispone de una normatividad comercial claramente proteccionista, ${ }^{17}$ misma que prevalece ante controversias originadas en las normas de los instrumentos de libre comercio signados por ese país (con toda la adjetivación aplicada a la cláusula 301). En segundo sitio, debe mencionarse el doble papel, complejo y contradictorio, de esa nación al aparecer como la potencia hegemónica mundial que promueve la globalización y, al mismo tiempo, como la economía central del hemisferio occidental en la confección del ALCA y, hasta el momento, en la operación del TLCAN, por no mencionar el carácter decisivo del que dispone en los tres organismos multilaterales de la globalización: el FMI, el Banco Mundial y la OMC. ${ }^{18}$

A este respecto, Stiglitz ofrece evidencias de la hipocresía estadounidense, en ocasión de predicar un evangelio y practicar su opuesto:

Rusia recibió un curso acelerado de economía de mercado, y nosotros fuimos los profesores. Fue un curso muy peculiar. Por un lado, recibieron grandes dosis de economía de libre mercado, de economía de libro de texto. Por otro lado, lo que vieron hacer en la práctica a sus profesores se alejó mucho de ese ideal. Les dijeron que la liberalización comercial era necesaria para una economía de mercado exitosa, pero cuando trataron de exportar aluminio y uranio (y también otros productos) a los Estados Unidos, se encontraron con la puerta cerrada. Evidentemente, EEUU había salido adelante sin liberalización comercial; o, como a veces se dice, "el comercio es bueno pero las importaciones son malas". Se les indicó que la competencia es vital (aunque no se puso en ello mucho énfasis), mientras que el gobierno de EEUU estuvo en el centro de la creación de un cartel global de aluminio, y concedió derechos de monopolio para la importación de uranio enriquecido al productor monopólico norteamericano. Se les aconsejó privatizar rápida y honradamente, pero el único intento privatizador de EEUU tomó años y años, y al final su integridad fue puesta en cuestión. Estados Unidos daba lecciones a todos, especialmente después de la crisis del Este asiático, sobre el "capitalismo de amiguetes" y sus riesgos. Pero el empleo de influencias resultó patente en varios casos. Si los sermones de Occidente no son tomados en serio en todas

17 Al respecto de esta normatividad, Paul Krugman y M aurice Obstfeld, opinan: “El Congreso aprobó hace poco la más importante de las leyes proteccionistas, la Omnibus Trade and Competitivenness Act de 1988, que endurece significativamente la política comercial estadounidense. A pesar de la oposición de la mayoría de los economistas al proteccionismo, éste sigue siendo tan fuerte como siempre, así que parece una posibilidad real que en los próximos años los Estados Unidos cambien bruscamente su largo compromiso de cuatro décadas con los principios del libre comercio". Paul R. Krugman y Maurice Obstfeld, Economía Internacional. Teoría y práctica, Madrid, M cGraw-Hill, 1994 , p. 6.

18 Esas trascen dentes y contradictorias tareas, hoy enfrentan la complicación adicional que deriva de la reacción frente a los actos terroristas del 11 de septiembre del 2001; reacción ciertamente complementaria a los reprobables afanes de Al-Qaeda, en opinión de William J. Perry, la más eficiente ONG del mundo. 
partes, deberíamos entender por qué. No se trata sólo de agravios pasados, como los injustos tratados comerciales. Se trata de lo que estamos haciendo hoy. Lo que los demás hacen es fijarse no sólo en lo que decimos sino también en lo que hacemos. No siempre es una imagen bonita. ${ }^{19}$

En este esquema, en el que resalta la incoherencia intelectual del FMI — escandalosa en el tratamiento de las crisis del sureste asiático, de Rusia, de Brasil y, recientemente, de Argentina-, al menos de cara a las tareas que debió desempeñar desde su origen, es conveniente subrayar un par de circunstancias que, bajo el influjo aparente de la neutralidad de los actores principales, muestran la falta de atención en las tareas ahora predominantes del FMI. Las políticas que, en el caso de Yeltsin, son evidentes y que, para todo efecto práctico en las negociaciones con el Tercer Mundo y con las naciones ex comunistas, invariablemente tendieron a favorecer a los acreedores y a sus socios.

\section{Los saldos visibles y las respuestas posibles}

Hasta ahora, más de una certeza mueve a afirmar que, como se ha mostrado, la globalización no arroja resultados plausibles: la extensión y ahondamiento de la pobreza, la desigualdad entre las naciones y en su interior, la magra lista de ganadores y la interminable de perdedores, las soberanías nacionales aplastadas, el páramo ambiental, la devastadora actividad del dinero caliente y, de manera especial, la rigidez de los organismos responsables para promover la estabilidad y el crecimiento de las naciones, visiblemente lejana de lo acordado en Bretton Woods.

Sin duda, las mejores razones para intentar la reforma de la globalización en curso, provienen del saldo, hoy visible, de los resultados del Consenso de Washington y su lamentable secuela en el tratamiento de las crisis derivadas de la libertad de acción del dinero caliente. De forma paradójicamente similar a la conformación de otro acuerdo —entre la política, la religión, la economía y el darwinismo, para apuntar hacia el laissez faire decimonónico; y de uno más, para combatirlo, entre terratenientes, sindicatos y monopolios-, hoy está a la vista un cuerpo de curiosas coincidencias. Este Consenso puede involucrar desde los infortunadamente bautizados globalifóbicos ${ }^{20}$ hasta el mandatario saliente del Brasil, Fernando Henrique Cardoso, sin menoscabo de los otros autores citados, pues trata sobre la necesidad no sólo de evocar, sino de invocar a Keynes (aquí y ahora también globalizado). El producto más reciente - y de mayor influencia política e intelectual—, es el texto de Joseph Stiglitz (2002), a quien — por sus cargos en el gobierno de William J. Clinton y en el Banco Mundial, y por la obtención del Premio Nobel de

\footnotetext{
Stiglitz, El malestar en la globalización, op. cit, p. 227.

20 Para corroborar las coincidencias mencionadas, confróntese el espléndido artículo de Susan George, "El movimiento global de ciudadanos", Foreing Affairs en español, M éxico, ITAM , primavera 2002, pp. 114-129.
} 
Economía - muy difícilmente se le puede considerar un radical enemistado con el capitalismo. Ese libro, El malestar en la globalización, ya ha producido algunos efectos de cambio en la actitud del FMI, por ejemplo, entre los regateos impuestos a la Argentina y la cortesía que empieza a experimentar Brasil. Después de casi tres décadas de improductivo desencuentro entre los nostálgicos de las herencias marxista y keynesiana, en la actualidad se abre un espacio para la convergencia.

La evocación de James Tobin, particularmente de su propuesta de gravar a la especulación con divisas, merece algo más que un recuerdo, una actualización y un sólido impulso para universalizar el trascendente impuesto, a la hora de buscar respuestas ante una globalización desbocada y sin rumbo. Una mención a la práctica malaya de aplicar impuestos al dinero que aspira a salir de los países con problemas críticos también debe tomar su sitio en la definición de componentes de otra globalización. Las reformas radicales del FMI - para ponerlo en el camino de regreso a las tareas que le asignó John Maynard Keynes, sin menoscabo de los éxitos de sus opositores en Bretton Woods: las de promover la expansión y el pleno empleo por todo el planeta- es un objetivo tan meritorio como indispensable que, además, exige la democratización de su proceso de toma decisiones y el establecimiento de las medidas necesarias para dotar de transparencia a las negociaciones y acuerdos que impulsa. Además, y de manera preponderante, resulta urgente destacar las tareas de la definición nacional, el espacio realmente democrático para que los afectados, todos ellos, eleven su voz opinando sobre las medidas con las que se da cumplimiento a la, hasta ahora errática, agenda de la globalización. ¿Cuánto empleo merece sacrificarse en aras del superávit comercial?, ¿cuánto deterioro ambiental resulta conveniente para incrementar el PIB?, ¿cuál es la magnitud del bienestar sacrificable, en beneficio de la competitividad?, en fin, ¿por cuánto tiempo deberá inmolarse la, de suyo magra, calidad de vida de los modernos condenados de la tierra, en aras de los ventajosos números negros de las grandes empresas multinacionales? Todo ello debe abordar la pertinencia, ritmo y expectativas de los llamados ajustes, impuestos por las hermanas gemelas que conducen el tratamiento fondomonetarista a los países pobres: la arrogancia y la ignorancia. Disponer de democracia en el capitalismo maduro - y en el tardío — no es lo mismo que gobernar democráticamente. ${ }^{21} \mathrm{Y}$ ahí se encuentra el más relevante problema de la globalización: si la ciencia, particularmente la exacta, no es un espacio propicio para la búsqueda de consensos, la política sí lo es.

21 B. Lechner, “¿Porqué la política ya no es lo que fue?”, Nexos, número 216, diciembre de 1995, citado en David Ibarra, El nuevo orden internacional. Esperanzas democráticas, soberanías marchitas, crisis financieras, M éxico, Aguilar, 1999, p. 24. 


\section{La fuerza de la historia}

El muy bien argumentado cuerpo de reformas plausibles y posibles, con el que Joseph Stiglitz concluye su Malestar en la globalización, se orienta a recuperar, por un lado, elementos del pasado, como la iniciativa original de Keynes para alumbrar el nacimiento del FMI y del Banco Mundial y, por otro, la célebre propuesta de James Tobin -el impuesto Tobin-, cuya única posibilidad para aplicarlo descansa en el acuerdo global de su universalización para hacer posible el gravamen sobre la especulación con divisas. Stiglitz propone novedades reformadoras que van desde la democratización, gobernabilidad y transparencia de los organismos de Bretton Woods y de la omc hasta la redefinición de intereses del FMI, cuya doble vocación - de cara a los propósitos estabilizadores de la economía mundial, y de servicio a los intereses predominantes de los acreedores de los países del Tercer Mundo y de los que creyeron habitar el segundo-, arroja un saldo de incoherencia intelectual y política con el que se han construido los notables fracasos del Fondo, con cargo al bienestar menguante de las sociedades afectadas: el este asiático, Argentina, México, Rusia y Brasil, entre otros.

Reformas de menor jerarquía, aunque igualmente urgentes, están referidas a normatividades similares en relación con las quiebras empresariales, la necesidad de que deudores y acreedores compartan riesgos y costos de los préstamos que - por turbulencias macroeconómicas, se conviertan en impagables_-, el establecimiento de mecanismos, justificaciones y procedimientos para condonar deudas de países sobreendeudados, y a la definición de formas de aseguramiento de los países deudores, relativas a variaciones considerables y no deseadas en los tipos de cambio.

Con independencia de las resistencias que, desde las instituciones de la globalización, se opongan a las propuestas reformistas, resulta conveniente precisar su pertinencia y, con ánimo clarificador, analizarlas en su dimensión histórica. En primer lugar, y por desgracia, debe recordarse que no fue John Maynard Keynes, sino Harry Dexter White el triunfador en Bretton Woods - tal y como su jefe Henry Morgenthau Jr. lo había calculado. ${ }^{22}$ La combinación de realismo diplomático y liberalismo económico, con la que Estados Unidos afrontó la Guerra Fría, se cocinó con un tipo de institucionalidad - la otan, el GatT, la onu y, en menor medida, el Plan Marshall- que desbordó al propósito keynesiano de promover el pleno empleo mundial estimulando, con liquidez internacional, la demanda efectiva de naciones sorprendidas por la recesión. Para el realismo resultaba imperativo afirmar un hecho histórico irrefutable: la Segunda Guerra mundial fue ganada por Estados Unidos y por la Unión Soviética, muy a pesar del otro hecho relevante: la disposición británica, de no perderla prácticamente en el arranque, durante la

22 Cf. Robert Skidel sky, John M aynard Keynes, Fighting for Freedom, 1937-1946, Nueva York, Penguin Group, 2000, pp. 337-374. 
primavera de 1940;23 este propósito estadounidense despejaba el tablero de la política internacional y colocaba en un segundo término al resto de aliados, con todo y Keynes.

De la conformación original de las instituciones de la posguerra resulta visible y recurrente la conducción, con voto de calidad y capacidad de veto, que Estados Unidos reservó para sí y que no comparte con nadie más. Antes de imaginar reformas, al margen de su urgencia, calidad y viabilidad, conviene recordar que, para ese país y sus gobiernos, los privilegios referidos forman parte de sus derechos soberanos. Un líder mundial puede y debe escuchar y promover reformas; un imperio, ni por asomo. ${ }^{24}$

\section{Denunciando y proponiendo}

En su descripción del globalismo neoliberal, Ülrich Beck encuentra diez significativos engaños de la corriente dominante, mientras que en sus propuestas reformadoras sugiere el mismo número de acciones por desarrollar, tal como se describe a continuación:

\begin{tabular}{ll}
\hline \multicolumn{1}{c}{ Engaños } & \multicolumn{1}{c}{ Propuestas } \\
\hline Metafísica del mercado mundial & Cooperación internacional \\
Comercio mundial libre & Estado transnacional \\
Internacionalización económica & Participación en el capital \\
Escenificación del riesgo & Reorientación de la política educativa \\
La ausencia de política & Compromiso empresarial con la democracia \\
El mito de la linealidad & Alianza para el trabajo ciudadano \\
Crítica del catastrofismo & La fijación de nuevos objetivos culturales, políticos y económicos \\
Proteccionismo negro & Culturas experimentales, mercados nicho y autorenovación social \\
Proteccionismo rojo & Empresarios públicos y trabajadores autónomos \\
Proteccionismo verde & Pacto social frente a la exclusión \\
\hline
\end{tabular}

Fuente: Elaboración propia con conceptos propuestos por Ülrich Beck, ¿Qué es la globalización?, op. cit., pp. 163-212.

En las elaboraciones del autor se propone reiteradamente el carácter de proyecto político del globalismo, presentado apolíticamente, como una suerte de requerimientos técnicos de la economía abierta y supuestamente próspera. Insiste, por ejemplo, en la presentación del binomio libre mercado-democracia, en tanto pareja inseparable y le opone la evidencia asiática, destacadamente la que ofrece China, en calidad de mentis rotundo a tal imagen ideológica.

23 Al respecto, se dispone del extraordinario texto de John Lukacs, Cinco días en Londres. Mayo de 1940, Madrid, FCE-Turner, 2001, 256 pp.

24 Ahí se encuentra una gran pregunta que se pretende resolver a lo largo del más reciente libro de Henry Kissinger, Does America Need a Foreing Policy. Toward a Diplomacy for the 21st Century, Nueva York, Simon \& Schuster, 2001, 318 pp. La cuestión está for mulada en los siguientes términos: America at the apex: Empire or Leader? 
La lógica de la argumentación de Beck discurre sobre el carácter creciente internacional de la economía, enfrentado al ámbito nacional de la política; el saldo de esta desigual confrontación no puede ser sino la de edificar con muy sólidas barreras la más amplia acción colectiva. La participación e instrumentos ciudadanos tienden a agotarse en el interior de las fronteras nacionales, mientras los intereses estrechos, egoístas, inmediatos y excluyentes de las grandes empresas se mueven y satisfacen por todo el planeta, sin restricción visible en el presente ni en un largo horizonte temporal. El problema, entonces, no sólo radica en las adversas condiciones que padece la sufriente humanidad, sino en las enormes dificultades y resistencias interesadas para modificarlas.

Entre las propuestas más directamente relacionadas con los preparativos de las naciones para insertarse en condiciones favorables en la globalización destacan las elaboradas por Ugo Pipitone. Este autor establece, con arreglo a sus trabajos de historia comparada, que los países que han logrado acelerar su historia y, así, salir del atraso, cumplieron con tres condiciones fundamentales, a saber: una agricultura exitosa, un amplio y sólido mercado interno y un Estado fuerte. ${ }^{25}$ Por su parte, y en su texto póstumo, Macur Olson hace referencia a la tríada de instituciones básicas para alcanzar la prosperidad: Estado de derecho, derechos individuales, con énfasis en los de propiedad —incluida la obligación inexcusable de cumplir los contratos-y depredación cero. ${ }^{26}$ Bajo éstas y otras lógicas, el Estado deberá reocupar, ahora con mayor talento y eficiencia, el espacio de tareas fundamentales que nadie más, mucho menos el mercado, se encuentra en posibilidades de cumplir; como sugieren Roberto Guimaràes y Alicia Bárcena:

De hecho, el papel del Estado es único, porque trasciende la lógica del mercado mediante la salvaguardia de valores y prácticas de justicia social y de equidad, e incorpora la defensa de los derechos difusos de la ciudadanía; necesario, porque la propia lógica de la acumulación capitalista requiere de la oferta de "bienes comunes" que no pueden ser producidos por actores competitivos en el mercado e indispensable, porque se dirige a las generaciones futuras y trata de procesos ambientales que no pueden ser sustituidos por capital o tecnología. ${ }^{27}$

Los predicadores del evangelio de los mercados competitivos y del Estado mínimo deberán comenzar a comprender, bajo estos imperativos, el precepto de Auguste Comte: "Sólo se destruye lo que se reemplaza". ${ }^{28}$

25 Ugo Pipitone, La salida del atraso. Un estudio histórico comparativo, M éxico, FCE, 1994, pp. 14-47.

26 Macur Olson, Poder y prosperidad. La superación de las dictaduras comunistas y capitalistas, M adrid, Siglo XXI, 2001, 203-235.

27 Roberto P. Guimaràes y Alicia Bárcena, "Desar rollo sustentable e imperativos de institucional idad", en La transición hacia el desarrollo sustentable. Perspectivas de América Latina y el Caribe, M éxico, INE-SEM ARNAT, UAM -X, PNUM A, 2002, pp. 15-34.

28 Citado en Marcel Merle, Sociología de las relaciones internacionales, Madrid, Alianza, 1986, p. 440. 


\section{Conclusiones}

Ante la voluntad política que ha impulsado de nuevo la libre competencia, la edificación de una globalización alternativa, por fuerza, deberá privilegiar la lucha en el terreno político, con el riesgo de caer en el engaño economicista del globalismo. No se trata, entonces, de vislumbrar solamente una alternativa económica viable y equitativa, sino de dotar a las relaciones internacionales, políticas, económicas y culturales de una cuota de legitimidad que, por la enorme lista de perdedores que arroja la versión en curso del laissez faire, no es una prenda visible en la globalización presente.

"Sin legitimidad no hay eficacia", tal cual lo sugiere Fernando Henrique Cardoso; ${ }^{29}$ y la cuestión relevante es preguntarse si — en las actuales condiciones de pobreza, desigualdad, imposición de políticas, páramo ambiental y enormes asimetrías en la toma de decisiones - la mayor parte de la humanidad considera positivo el desorden globalizado o si, como hasta ahora se ha pretendido, la legitimidad es un adorno prescindible y redundante. La respuesta a ambas cuestiones es una rotunda negativa. Esta globalización no es legitimable ni legítima, y ésta es indispensable. El mundo puede encaminarse a un orden próspero, pacífico, legítimo y sustentable bajo los principios democráticos y los valores universalmente compartidos, mas no impuestos; reconociendo, respetando y promoviendo las diferencias religiosas, culturales, políticas y económicas, en tanto derechos soberanos de cada nación. Hoy, como ayer, las fuerzas que han impulsado el predominio de la globalización, invariablemente descansan en el aspecto económico, un impulso clave en la intención de universalizar a personas, culturas y naciones. Un camino - hoy alternativo, posible, despojado del predominio de los intereses de las grandes corporaciones multinacionales- está a nuestro alcance. Regular cuanto sea necesario, con arreglo a los intereses de la población mayoritaria; distribuir de la forma más conveniente para impulsar el consumo y, con él, la producción y el empleo; brindar certidumbre a los habitantes, en sus vidas, en sus patrimonios y recuperar la relevante tarea de gobernar de cara a los gobernados son ingredientes ciertos de una alternativa posible.

Un programa que conduzca al asunto económico a su condición secundaria, que privilegie el tema relevante del amplio espectro de las relaciones humanas — desde la importancia de las cuestiones de género hasta el hoy incómodo tema del consumo de drogas, pasando por el desarrollo preferente de medidas preventivas en contra de la delincuencia y no sólo de su represión- está en nuestras manos. El asunto importante, hoy casi el único, reside en la disposición de las fuerzas de la causa alternativa —individuos, partidos, organizaciones sociales y pobres - a subordinar sus prioridades particulares, sus intereses excluyentes, para evitar la puesta en escena de las divisiones, con las que - de

29 Fernando H. Cardoso, "La globalización y los desafíos de la democracia en el plano internacional, Foreign affairs en español, M éxico, ITAM , primavera 2002, p. 112. 
tiempo atrás - cuentan los beneficiarios de la penuria que ya vivimos y de las que se le han ofrecido evidencias incontables; disponernos a vivir, en fin, sin temores frente a la felicidad por construir. ¿Será posible?

\section{Bibliografía}

Ayala E., José, Mercado, elección pública e instituciones. Una revisión de las teorías modernas del Estado, México, Miguel Ángel Porrúa-FE-UNAM, 1996.

Beck, Ülrich, ¿Qué es la globalización?, Barcelona, Paidós, 1998.

Bolaños G., Wilfrido R., Cuatro enfoques sobre la globalización, UAM-X, 2002, mimeo.

Cardoso, Fernando H., La globalización y los desafios de la democracia en el plano internacional, Foreing Affairs en español, México, IтAM, primavera 2002.

Ferguson, John M., Historia de la economía, México, FCE, 2002.

Ferrer, Aldo, Historia de la globalización II. La revolución industrial y el Segundo Orden Mundial, Buenos Aires, FCE, 2000.

García Canclini, Néstor, La globalización imaginada, México, Paidós, 1999.

George, Susan, El movimiento global de ciudadanos, Foreing Affairs en español, México, ItAm, primavera 2002.

Gray, John, Falso amanecer. Los engaños del capitalismo global, Barcelona, Paidós, 2000.

Guimaràes, Roberto P. y Alicia Bárcena, "Desarrollo sustentable e imperativos de institucionalidad", en La transición hacia el desarrollo sustentable. Perspectivas de América Latina y el Caribe, México, INE-SEMARNAT, UAM-X, PNUMA, 2002.

Ibarra, David, El nuevo orden internacional. Esperanzas democráticas, soberanías marchitas, crisis financieras, México, Aguilar, 1999.
Keynes, John Maynard, "El fin del laissez faire (1926)", en Ensayos de persuasión, Barcelona, Crítica, Grijalvo, 1988.

Kissinger, Henry Does America Need a Foreing Policy. Toward a Diplomacy for the 21st Century, Nueva York, Simon \& Schuster, 2001.

Krugman, Paul R. y Maurice Obstfeld, Economía Internacional. Teoría y práctica, Madrid, McGraw-Hill, 1994.

Laïdi, Zaki, Un mundo sin sentido, México, FCE, 1997.

Lukacs, John, Cinco días en Londres. Mayo de 1940, Madrid, FCE-Turner, 2001.

Merle, Marcel, Sociología de las relaciones internacionales, Madrid, Alianza, 1986.

Olson, Macur, Poder y prosperidad. La superación de las dictaduras comunistas y capitalistas, Madrid, Siglo XXI, 2001.

Pipitone, Ugo, La salida del atraso. Un estudio histórico comparativo, México, FCE, 1994.

Polanyi, Karl, La gran transformación. Los orígenes políticos y económicos de nuestro tiempo, México, FCE, 1992.

Skidelsky, Robert, John Maynard Keynes. Fighting for Freedom, 1937-1946, Nueva York, Penguin Group, 2000.

Stiglitz, Joseph E., El malestar en la globalización, Madrid, Taurus, 2002.

Viner, Jacob, The Customs Union Issue, Nueva York, Carnegie Endowment for International Peace, 1950 . 